\title{
IMPLEMENTASI SENSOR CAHAYA SEBAGAI PENGONTROL KESEIMBANGAN ROBOT BERODA DUA MENGGUNAKAN KONTROLER PID
}

\author{
Barlian Henryranu P. ${ }^{1}$, Wijaya Kurniawan ${ }^{2}$, Bayu Priyambadha ${ }^{3}$ \\ ${ }^{1,2,3}$ Program Studi Sistem Komputer, Universitas Brawijaya \\ Email: ${ }^{1}$ barlian@ub.ac.id, ${ }^{2}$ wjaykurnia@ub.ac.id, ${ }^{3}$ bayu_priyambadha@ub.ac.id \\ (Naskah masuk: 2 Desember 2013, diterima untuk diterbitkan: 17 Februari 2014)
}

\begin{abstract}
Abstrak
Dengan menggabungkan Sistem Kontrol, sensor dan motor Servo diharapkan Robot segway dapat direalisasikan. Dalam penelitian ini Sistem Kontrol yang digunakan adalah metode PID, sedangkan sensor yang akan digunakan adalah cahaya yang merepresentasikan sudut kemiringan terhadap bumi. Dengan input berupa Error sudut dan Del Error sudut terhadap bumi maka didapatkan hasil PID kontroller berupa angular rate yang digunakan untuk mengontrol kedua rodanya. Robot Segway memiliki rise time/fall time, settling time dan Robot Segway mampu mencapai kesetimbangannya kembali (steady state) setelah mendapatkan gangguan dari luar.
\end{abstract}

Kata kunci: Robot kesetimbangan, sensor cahaya, PID kontroler

\section{Abstract}

By combining the Control System, sensors and Servos motors are expected to Segway can be realized. In this research use the PID method, while the sensor to be used is the light that represents the elevation angle of the earth. With the input is angel Error and angel Del Error of the earth then the results obtained in the form of angular rate PID Controller is used to Control the two wheels. Segway Robot has a rise time / fall time, settling time and Segway Robot can reach the balance again (steady state) after get a outside disturbance.

Keywords: Self-balancing robot, light sensor, PID Controller

\section{PENDAHULUAN}

Penelitian tentang robot balancing telah mendapatkan perhatian selama dekade terakhir di sejumlah laboratorium robotika di seluruh dunia. Penelitian ini terinspirasi beberapa penggemar robot untuk mengembangkan kedua produk industri swasta dan publik.

Robot yang bekerja dengan kemampuan untuk menyeimbangkan diri pada dua roda dan berputar di tempat ini merupakan terobosan mutakhir yang memungkinkan sistem navigasi yang mudah pada berbagai medan. Kemampuan ini memiliki potensi untuk memecahkan sejumlah tantangan dalam industri dan masyarakat. Penggabungan Platform teknologi robot pada akhirnya akan muncul sebagai cara baru dan terobosan mobilitas dalam aplikasi robot. Misalnya, kursi roda bermotor memanfaatkan ini teknologi akan memberikan terobosan kemampuan operator yang lebih besar. Sebuah alat kecil yang dibuat memanfaatkan teknologi ini memungkinkan membantu manusia untuk perjalanan jarak pendek di daerah kecil atau pabrik sebagai pengganti menggunakan mobil.

Penelitian ini akan menyelidiki robot balancing roda dua, yang akan digunakan sebagai test untuk menguji penggunaan Legway robot dengan sensor cahaya menggunakan kontroller PID. Robot ini akan menjadi model dan sebagai pemecahan masalah. Algoritma kontrol yang akan diteliti sebagai bagian dari balancing robot adalah kontroler proporsionalintegral-derivatif. Selama ini mikrokontroler telah menjadi lebih cepat, lebih murah dan lebih handal. Sebuah mikrokontroler yang terangkum dalam sebuah robot lego NXT akan menjadi pilihan untuk melaksanakan algoritma kontrol ini. Algoritma akan diprogram menggunakan bahasa pemrograman tingkat tinggi $C$. Kesesuaian dan kinerja dari algoritma kontrol akan diteliti. Algoritma kontrol PID akan digunakan pada robot balancing untuk pengontrol sistem.

Sensor adalah piranti yang sangat penting pada sistem kontrol digital robot. Pada penelitian ini sensor yang digunakan robot adalah sensor cahaya. Sensor cahaya adalah suatu piranti yang dapat menerima masukan patulan cahaya sehingga dapat merepresentasikan jarak pantulnya. Sensor akan memberikan data yang cukup akurat yang akan digunakan oleh robot untuk mendapatkan informasi sudut kemiringan.

Kontrol dan algoritma balancing yang semua akan ditulis dalam perangkat lunak dan diimplementasikan pada robot lego NXT. Penggunaan utama dari robot lego adalah untuk sebagai objek uji. Pada penelitian ini dibatasi pada kondisi set poin awal. Kondisi awal meliputi intensitas cahaya sekitar, fisik permukaan lantai dan anggapan set poin zero. 


\section{METODE PENELITIAN}

Metode yang digunakan dalam sebuah penelitian sangat mempengaruhi kinerja sistem penelitian untuk dapat bekerja secara optimal.Dalam sebuah penelitian, metode yang sesuai dengan kebutuhan diharapkan dapat berjalan dengan baik, sehingga bisa mengikuti metode atau prosedur yang diberikan. Metodologi yang dilakukan dalam penelitian ditunjukkan dalam gambar 1 .

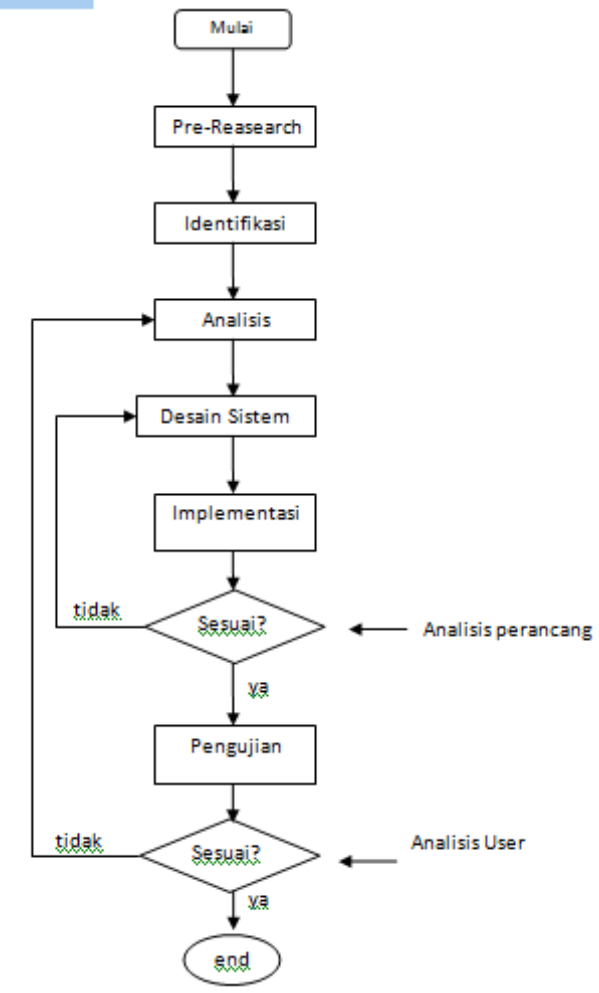

Gambar 1. Flowchart Metode Penelitian

Flowchart Metode Penelitian

1. Pre Research

Pada bagian ini dilakukan penelitian secara umum tentang pokok bahasan yang akan dilakukan pada penelitian.

2. Identifikasi

Identifikasi yaitu mengidentifikasi masalah dengan batasan yang jelas dengan menggunakan teknik :

3. Studi Pustaka

Mencari buku referensi yang dapat membantu dalam hal ini buku yang mempelajari sistem balancing.

4. Observasi

Observasi ini dilakukan terhadap objek secara langsung guna mendapatkan informasi dasar terhadap objek yang diteliti.

5. Analisis

Setelah semua data diperoleh melalui tahap identifikasi, kemudian merancang robot lego dan desain software.

6. Desain Sistem
Merancang sistem secara keseluruhan mulai dari desain robot, struktur mekanik robot, software, menghasilkan output sebuah kesimpulan.

7. Implementasi

Memindahkan hasil rancangan pada tahap sebelumnya kedalam sistem.

8. Pengujian

Dalam tahap ini dilakukan uji coba perangkat keras dan perangkat lunak.

\section{HASIL DAN PEMBAHASAN}

\subsection{Perancangan State pada Loop Kontrol}

Setelah menentukan loop kontrol, maka kita harus menentukan fungsi error. Representasi ruang state digunakan untuk menentukan state. State disini yang akan digunakan untuk mendefinisikan sistem melalui persamaan diferensial yang menggambarkan dinamika plant kontrol. State awal yang ditentukan ini digunaan dalam implementasi robot. Parameter yang digunakan meliputi empat hal, yang merupakan sudut kemiringan, Y, kecepatan sudut, Y'(turunan pertama), posisi Platform sudut, F, dan Platform kecepatan sudut, M' (turunan pertama).

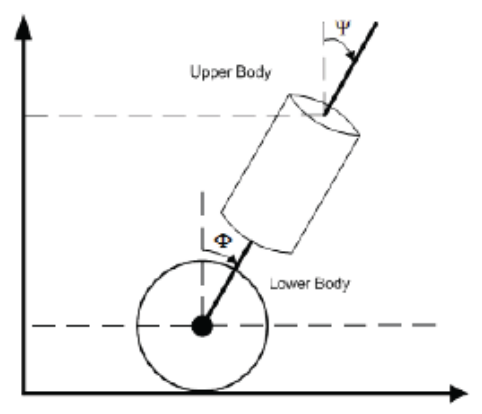

Gambar 2. Inverter Pendulum

Logikanya, robot harus bisa menggerakkan roda searah dengan tubuh bagian atas robot agar robot seimbang. Karena itu pembacaan sensor sangat dibutuhkan untuk mengetahui posisi roda dan tubuh bagian atas untuk menjaga roda bagian bawah robot tepat pada pusat gravitasi. Dari sudut pandang matematika, titik kontrol adalah linearisasi persamaan orde dua non-linear (persamaan diferensial pendulum terbalik) dan oleh karena itu pendekatan turunan pertama akan mencakup kelengkungan/kecepatan putar juga. Dari sudut pandang praktis, kelengkungan/kecepatan menunjukkan bagaimana cepat robot bergerak dari titik steady state dan kondisi ini sangat relevan untuk mengurangi error dengan meningkatkan kecepatan secara relatif terhadap osilasi selama balancing (Rieper. J, 2009). 


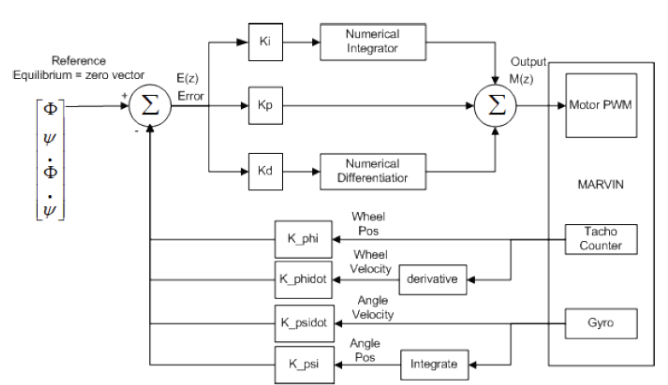

Gambar 3. PID Kontroller Loop tertutup

\subsection{Parameter dan Stabilitas}

Perhitungan parameter kontrol PID yang tepat sangat penting untuk membuat sistem yang stabil. Ini dikenal dengan istilah loop tuning. Jika loop tuning tidak dilakukan dengan sesuai, sistem kontrol akan menjadi tidak stabil sehingga output akan menyimpang. Osilasi mungkin bisa menjadi sangat menggaggu sistem (Trussel.M, 2009). Satu-satunya hal yang akan mencegah penyimpangan atau osilasi adalah mempercepat titik jenuh. Hal ini sering terjadi ketika mencoba untuk menghasilkan robot segway dan umumnya bukan suatu masalah karena integritas struktural, namun jika kontroller digunakan untuk mengendalikan sesuatu yang lain mungkin akan terjadi osilasi pada desain robot karena akan selalu menghindari titik referensi. Loop tuning dapat didefinisikan sebagai penyesuaian parameter nilai kontrol (Proporsional (P), Integral (I) dan Derivatif (D)) untuk mengoptimumkan respon kontrol yang diinginkan. Gambar 4 menunjukkan diagram pole zero (Rieper. J, 2009).

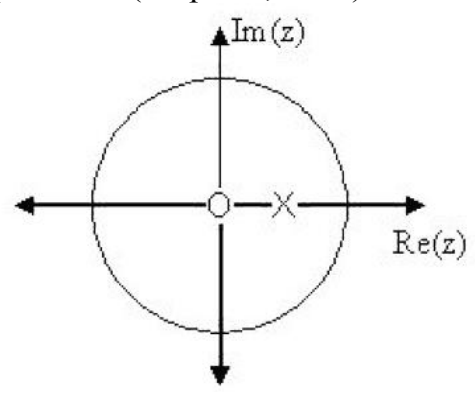

Gambar 4. Pole Zero

Pole di representasikan dengan sebuah silang dan zero dengan lingkaran. Metode yang dapat digunakan berkisar antara tidak ada pengetahuan sistem untuk simulasi penuh dari sistem yang dapat digunakan untuk menghitung stabilitas dan mengatur parameter yang tepat dari kontroler PID untuk kinerja optimal. Ada 2 parameter tuning yaitu tala online dan offline. Tala online berarti tuning ketika sistem sedang berjalan. Itu berarti satu parameter menyesuaikan sementara sistem sedang berjalan. Tala Offline berarti mengambil kontrol diluar plan, menyesuaikan parameter dan kemudian kembali mengabungkan sistem. Ini adalah metode yang telah kami digunakan. Robot telah dihentikan, parameter diatur dalam software, dan terakhir firmware baru telah diunggah. Tala online bisa digunakan dengan link USB antara robot dan PC dari mana parameter baru bisa di-upload dengan cepat (Rieper. J, 2009).

\subsection{Tuning Robot}

Ini adalah percobaan dan pendekatan error. Prosedurnya adalah sebagai berikut (Gunterus, 1994).:

- Mengatur I dan D menjadi nol

- Meningkatkan P sampai output dari loop berosilasi

- Mengatur P pada setengah penguatan yang diperoleh pada langkah sebelumnya.

- Meningkatkan I sampai steady state offset benar. Jika terlalu banyak akan membuat sistem tidak stabil

- Meningkatkan D untuk mendapatkan waktu sistem stabil lebih cepat.

Langkah-langkah ini dapat digunakan untuk menyempurnakan sistem dan lebih baik untuk melakukannya pada sebuah sistem secara langsung.

Tabel 1 menunjukkan efek meningkatkan parameter yang digunakan untuk fine tuning robot (Rieper. J, 2009).

Tabel 1. Parameter tuning

\begin{tabular}{|c|c|c|c|c|}
\hline Parameter & Rise Time & Overshoot & $\begin{array}{l}\text { Settling } \\
\text { Time }\end{array}$ & $\begin{array}{l}\text { Error } \\
\text { Steady } \\
\text { State }\end{array}$ \\
\hline Kp & Menurun & Meningkat & Menurun & Menurun \\
\hline $\mathrm{Ki}$ & Meningkat & Meningkat & Meningkat & $\begin{array}{l}\text { Menurun } \\
\text { sampai } 0\end{array}$ \\
\hline $\mathrm{Kd}$ & Menurun & Menurun & Menurun & Tidak ada \\
\hline
\end{tabular}

Sebenarnya sinyal kontrol adalah perkalian error dikalikan dengan Kp tetapi ternyata dari hasil percobaan terdapat keterbatasan robot lego pada prosesornya yang mempunyai lebar bus 8 bit. Dalam pemrograman c 8 bit kecepatan motor direpresentasikan dalam kode biner antara 0-255 (Per. J, 2009). Karena sinyal kontrol langsung digunakan untuk mendrive motor maka dapat disimpulkan bahwa untuk menentukan $\mathrm{Kp}$ harus menghasilkan kecepatan yang berada pada range kecepatan motor antara 0-255 (inparmix, 2010). Untuk menjaga kestabilan robot maka range diperkecil menjadi $1 / 2$ kali range kecepatan robot yaitu 127. Ternyata ketika diuji cobakan maka kecepatan motor dengan nilai 127 adalah dengan nilai Kp sebesar 70 .

Setelah menentukan Kp maka diujikan hasil respon robot dengan nilai $\mathrm{Ki}=0$. Kemudian dari hasil pengujian dilihat respon robot terhadap ketidakseimbangannya. Sehingga perlu ditambahkan $\mathrm{Ki}$ agar error bisa nol tetapi jangan terlalu besar karena bisa memperlambat respon robot. Dari hasil percobaan didapatkan Ki terbaik adalah 0,5.

$\mathrm{Kd}$ digunakan untuk mengkompensasi nilai $\mathrm{Ki}$ yang lambat merespon ketidakseimbangan robot. 
Tetapi jika Kd terlalu besar maka akan mengakibatkan terlalu sensitive terhadap penyimpangan steady. Dari hasil trial error didpatkan nilai Kd optimal sebesar 20 dimana robot bisa steady dan dapat merespon cukup cepat.

Pada percobaan awal, robot didesain sesuai dengan robot yang akan diimplementasikan. Untuk mengambil data pengukuran sensor dan power motor dilakukan dengan menjalankan sistem sekaligus menyambungkan robot dengan kabel ke dalam PC. Gambar 5 menunjukkan kondisi ketika pengambilan data. Tabel 2 memperlihatkan data yag diperloleh ketika percobaan.

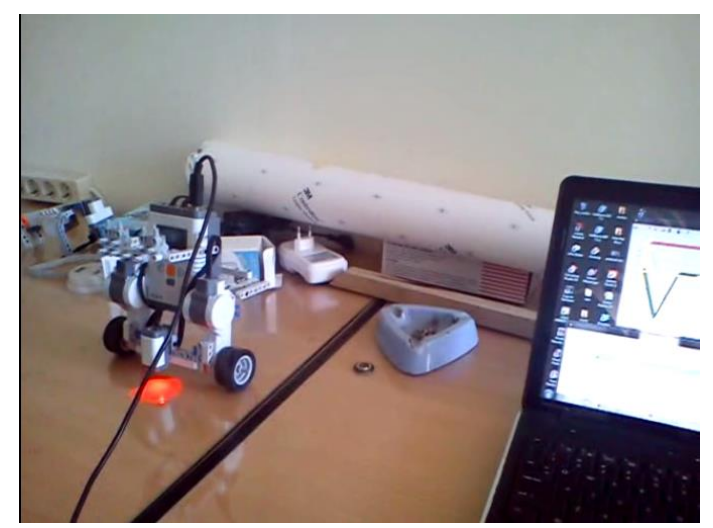

Gambar 5. Percobaan Ambil Data

Tabel 2. Data Percobaan

\begin{tabular}{rrrr}
\hline time & sensor & $\begin{array}{c}\text { power motor } \\
\text { kanan }\end{array}$ & $\begin{array}{c}\text { power } \\
\text { motor kiri }\end{array}$ \\
\hline 1 & 48 & 20 & 0 \\
2 & 48 & 70 & 70 \\
3 & 48 & -120 & -70 \\
4 & 48 & 70 & -10 \\
5 & 48 & 20 & -90 \\
6 & 48 & 20 & 20 \\
7 & 48 & 50 & 130 \\
8 & 48 & -70 & -70 \\
9 & 48 & 0 & 0 \\
10 & 48 & 70 & 0 \\
\hline & & &
\end{tabular}

Pengambilan data (tabel 2) diperoleh dari trial error pada awal percobaan untuk data set poin sensor. Disini mempunyai anggapan bahwa pada set poin tersebut sensor mendeteksi kesetimbangan robot. Kemudian menjalakan code program yang sudah terinjeksi dalam robot dengan menggunakan parameter trial error pada awal percobaan. Untuk dapat mengetahui respon robot, maka robot dihubungkan dengan kabel USB ke computer menggunakan program aplikasi lego. Hasil rekaman data (tabel 2) menunjukkan bahwa parameter robot seperti power motor kiri dan kanan serta parameter sensor dapat direkam dengan jelas. Sampling parameter robot sebanyak 100 time yang dapat dijadikan data referensi sehingga dapat digunakan sebagai parameter kesimpulan lajutan untuk dapat memperbaiki set poin yang telah diperoleh sebelumnya.

\section{PENUTUP}

Dari hasil pengujian telah diketahui kebutuhan menghadirkan prototype awal alat transportasi alternatif yang menggunakan energi listrik. Dalam merealisasikan penelitian tersebut, ada beberapa hasil yang diperoleh sehingga dapat digunakan sebagai kesimpulan sebagai berikut:

- Membuat robot dapat berdiri secara setimbang tidak berpenumpang hanya dengan menggunakan kedua rodanya dapat dibuat dengan menggunakan sensor warna.

- Algoritma PID dapat menyeimbangkan sistem dengan memanfaatkan informasi sudut elevasi yang didapatkan.

- Dari hasil percobaan didapatkan bahwa untuk model robot lego NXT dan lokasi percobaan digunakan $\mathrm{Kp}=70, \mathrm{Ki}=0,5$, dan $\mathrm{Kd}=20$

- PID kontrolller dapat mengeluarkan output dalam bentuk yang dapat digunakan untuk mempertahankan kesetimbangan.

Berdasarkan hasil pengujian didapatkan saransaran sebagai berikut:

- Sensor warna dapat digunakan sebagai masukan kesetimbangan robot hanya saja memerlukan konsistensi intensitas cahaya yang konstan sehingga untuk mendapatkan hasil yang optimal disarankan menggunakan sensor gyro dan accelero.

- Karena ketidakkonsistenan intensistas cahaya yang diterima maka disaran menambahkan sebuah filter untuk dapat menentukan parameter P,I,D yang lebih akurat

- Penelitian ini merupakan penelitian dasar untuk menjaga kesetimbangan robot, sehingga untuk kedepannya robot tidak hanya bisa menjaga kesetimbangan saja tetapi dapat membuat robot dapat berjalan pada track.

\section{Daftar Pustaka}

GUNTERUS, F. 1994. Falsafah Dasar Sistem Pengendalian Proses. PT Elex Media Komputindo. Jakarta.

RIEPER, J. 2009. Marvin-The Balancing Robot.

PER, JONSSON. 2009. Two Wheeled Balancing Lego Robot.

TRUSSEL, M. 2009. Engaging with the NXT Prototype Board. Spring Term. Swiss Federal Institute Technology of Zurich.

www.inpharmix.com. 2010. A PID Kontroller For Lego Mindstorms Robots". http://www.inpharmix.com/jps/PID_Kontro 1ler_For_Lego_Mindstorms_Robots.html. 